Resumen por el autor, Juan C. Nañages,

Universidad de Filipinas.

Dos casos de corazon monoventricular con atresia y transposición de algunas de las raices de los grandes vasos.

En 118 corazones de niños filipinos, estudiados por el autor con referencia al orificio oval (foramen ovale) se hallaron dos corazones monoventriculares. La presente contribución presenta una descripción morfológica de estos dos casos de corazón monoventricular, encontrados en dos varones, uno de ellos de dos horas, el otro de cuatro dias de edad. En el primer caso se comprobó la existencia de un ventrículo derecho sumamente pequeño, con el tabique interventricular desplazado y el orificio atrio- ventricular derecho ocluido. En el segundo caso se not 6 la existencia de un tabique interventricular incompleto, acompañado de ausencia completa del orificio mitral. El autor discute ambos corazones con relación a su probable desarrollo y fisiología. Los casos de corazón monoventricular son compatibles con el desarrollo intraruterino normal, pero cuando están asociados con estenosis pulmonar, aún en el caso de existir un conducto arterial patente, la vida puede mantenerse tan solo durante unas pocas horas después del nacimiento.

Translation by Jose F: Nonidez 
TWO CASES OF MONOVENTRICULAR HEART WITH ATRESIA AND TRANSPOSITION OF SOME OF THE ROOTS OF THE GREAT VESSELS

\author{
JUAN C. NANAGAS \\ Department of Anatomy, University of the Philippines \\ EIGHT FIGURES (TWO PLATES)
}

In the course of a series of examinations that the writer undertook on a collection of Filipino infant hearts, for the special study of the foramen ovale, he encountered among 118 two instances of peculiar abnormalities that were thought of sufficient interest not only from the embryological viewpoint, but also from their physiological importance in relation to the viability of the fetus, as to warrant this brief descriptive report.

Congenital malformations of the heart do not usually interest many readers of medical literature, for the reason that they are often classed as "mere developmental curiosities of the human organism" devoid of special clinical significance to the general practitioner. Though this may be true to a certain extent in the two cases that I am now reporting, nevertheless, it must be borne in mind that some of these instances of defective cardiac development are quite compatible with life, and are of sufficiently common occurrence as to render their recognition not only important, but even essential to clinical medical men. Cases have been recorded where individuals have lived for years with cardiac malformations. In life, these patients must have undoubtedly exhibited definite but undiagnosed clinical pictures, which could have been recognized and a more rational treatment prescribed had their clinical consideration been carried in conjunction with corresponding anatomical and physiological studies. Gladstone, in his paper on cardiac malformations, emphasizes particularly this point when among other things he stated: 
It is of greatest importance that the signs and symptoms produced by these different types of cardiac malformation should be carefully studied in all cases and recorded, so that an opportunity will be afforded of comparing one case with another, and of diagnosing the kind of abnormalities during life. In order to complete our knowledge of these cases, however, it remains for clinicians to correlate the signs and symptoms which these different malformations of the heart produce. It will then be possible to recognize the type of malformation during the patient's lifetime, and to carry out the treatment of individual patients upon a rational basis.

It is intended to present in this paper, first, the anatomical conditions of the abnormalities found in each case, and then to offer a tentative explanation of their possible embryological origin and the probable cardiac circulations occurring during intra and extra-uterine life.

\section{ANATOMICAI FINDINGS}

Case 1. The first specimen was the heart of a male Filipino infant that lived only two hours after birth. The case came to the city morgue from one of the health districts of the city, and for this reason no clinical history could be obtained except that the baby lived for about two hours. In opening the heart by routinary incisions I was surprised to observe that there were only three cardiac chambers, viz., the right and left auricles and a considerably enlarged ventricle. External examination showed that what should have been considered at a glance as the trunk of the pulmonary artery, with its prominent anterior position and left upward course, was really the ascending root of the aorta with its wide communication to the single ventricle. The real pulmonary artery was found only after a careful search, as a small poorly developed vessel on the left anterior side of the aortic trunk closely adherent to it, and apparently, from the outside at least, continuous with the base of the ventricle (fig. $1, B$ and $C$ ). The great cardiac vein together with the anterior coronary artery, that normally course downward to the apical notch of the heart, were considerably shifted to the right of the median line running obliquely to the right border of the ventricle (fig. 1, A). 
This heart weighed 17.2 grams, or 0.81 per cent of the body weight, the latter being 2,114 grams. Its greatest circumference taken at the base of the ventricle was $96 \mathrm{~mm}$. and its longest diameters were $46 \mathrm{~mm}$. vertically, $37 \mathrm{~mm}$. transversely, and 21 $\mathrm{mm}$. anteroposteriorly. The ratio of the weight of the heart to the body weight in this case is a trifle greater than the normal ratio as given by Jackson ( 0.77 per cent) and Vierordt ( 0.76 per cent) in newly born infants. The difference of 0.04 to 0.05 per cent is in reality sufficiently small to warrant the conclusion that this heart, at least in weight, has attained its normal state of development.

On careful internal examination of the single ventricle no trace could be seen of the existence of any separation of this chamber into right and left halves. The right lateral wall, however, showed a marked thickening of the cardiac musculature, which extended medially, as far as a line coinciding externally, with the oblique course of the anterior coronary artery described above (figs. 2 and 3). An anteroposterior cut through the thickness of this part of the wall showed the muscle fibers in close relation anteriorly and superiorly with the rudimentary trunk of the pulmonary artery, from which point they appeared to stream obliquely downward and posteriorly. The excessive thickness of this part has produced a corresponding internal swelling into the cavity of the ventricle at its right lateral side. This fact would seem to indicate that this internal swelling probably represented the rudiment of an interventricular septum which might have become arrested in its development.

The single ventricle in this heart therefore is in reality the left ventricle which had become compensatingly enlarged. In the cavity of the ventricle there were found two large and several small papillary muscles and many trabeculae carnae (figs. 2 and 3). The principal papillary muscles were normal in location for the left ventricle, one of them arising from the left anterior wall and the other from the posterior wall. The cordae tendinae from these papillary muscles extended to the medial angles of the anterior and posterior cusps of the mitral valve and were attached to their margins. 
The circumference of the left auriculoventricular orifice in this case was $35.5 \mathrm{~mm}$. From cardiac measurements of ninetysix still-born infants made by me I had obtained a normal average of $24.5 \mathrm{~mm}$. for the circumference of this opening. It seems, therefore, that the excess of $11 \mathrm{~mm}$. would be accounted for by the fact that this orifice's being the only communication between the auricles and the ventricle it had probably become compensatingly enlarged.

The other communication that the single ventricle had was with the aorta. The circumference of this aortic orifice measured $16.5 \mathrm{~mm}$., a little more than my normal average figure, which was $14 \mathrm{~mm}$. This opening was guarded by three semilunar cusps, two anterior, slightly shifted to the left in the direction of the pulmonary artery, and one posterior. Each of these cusps showed well-developed sinuses, from two of which the right and left coronary arteries originated as in normal cases. The vessel leading from the ventricle through this orifice, though from its external position would correspond to the pulmonary artery, is nevertheless undoubtedly the aorta because of the facts above considered, viz., the position of the guarding semilunar valves and the origin of the coronary arteries and because of the greater thickness of its wall.

The right auriculoventricular orifice examined from the auricular side is oval in shape with its long axis directed transversely and its circumference measuring approximately $17 \mathrm{~mm}$. Its margins are sharply defined and the flaps of the valve were completely fused together forming a $7-\mathrm{mm}$. pit underneath the orifice. Several small openings were found at the bottom of this pit which on a sagittal section showed them to open into blind crevices lodged in the right thickened part of the ventricular wall (figs. 2 and $3, C$ ). This fact seems to further confirm the statement that the medial portion of this thickened wall represented a rudimentary interventricular septum. The crevices into which the openings of the flaps led were probably the remains of an imperfectly developed right ventricle, which conclusion is still more justified by the organic connection of the fibers of the ventricular wall in this neighborhood and the roof of the obliterated 
pulmonary artery as previously recorded. The bundles of fibers found between these crevices were possibly diminutive papillary muscles.

The imperfectly developed trunk of the pulmonary artery was only about one-fifth the size of that of the aorta and was partly hidden from view by the left auricular appendix. On opening the artery proximally it was found to terminate blindly in three small sinuses which did not appear to have any connection with either the ventricle or the crevices found beneath the occluded right auriculoventricular orifice. Two of these sinuses were posterior and slightly medial in position, while the other was anterior. They were limited by three embryonic semilunar valves fused together and exhibiting thickened borders at the lines of fusion. Below this level the ventricular wall appeared on section to be entirely solid; the infundibulum or conus arteriosus was therefore entirely arrested in its formation. From the right posterior wall of the pulmonary artery about $2 \mathrm{~cm}$. from its root arose the patent ductus arteriosus, which was about as large as the pulmonary trunk itself and established a free communication with the ascending aorta (fig. 1).

The foramen ovale was patent, the aperture between the free edges of the independent septum primum and septum secundum measured $4 \mathrm{sq}$. $\mathrm{mm}$. The septum primum, however, was greatly relaxed, bulging considerably into the left atrium. This condition was possibly due to the irremediable free flow of blood from the right to the left sides of the heart.

Case 2. This heart was that of a poorly nourished full-term male Filipino baby that lived only four days postpartum. It showed harelip and polydactilism of both hands. Its body weight was 1,640 grams, sitting height $30 \mathrm{~cm}$. and standing height $46 \mathrm{~cm}$.

It will be noticed that the body weight in this case was far below the average given for normal newly born European and American babies as given by various investigators (over 3,000 grams) and a little below the average obtained by me for apparently normal Filipino still-born babies (2,200 grams). 
Its standing height was only a trifle below the average figures given for American and European still-born babies, which was about $49 \mathrm{~cm}$.

The differences of these two measurements from the normal averages would seem to indicate that while the development of the body was about normal, it was undoubtedly ill nourished.

From the shape of the heart alone one would readily anticipate the presence of some abnormalities. The vertical diameter was markedly in excess to the width. It weighed 17.7 grams, or 1.07 per cent of the body weight. This ratio was higher than in our first case and considerably greater than the figures given by Jackson and Vierordt. The greatest circumference of this heart was $92 \mathrm{~mm}$., the largest vertical diameter was $47 \mathrm{~mm}$., the transverse $36 \mathrm{~mm}$., and the anteroposterior $26 \mathrm{~mm}$.

The anterior surface represented by the anterior half of the right atrium and the ventricle was massive and much larger than the posterior surface. It was divided into a larger triangular right anterior facies and a narrower roughly quadrangular surface at the left by a linear elevation of the ventricular wall running from the base above to the apex of the ventricle below. The wall of the ventricle at the upper end of this right anterior portion was elevated in a marked upward prominence considerably deepening the auriculoventricular sulcus at this point (fig. 4).

The conus arteriosus was entirely absent and the pulmonary artery could not be seen on the normal point of its origin from the ventricles. The only vessel seen originating directly from the latter was the aorta, which appeared much larger than normal, and its ascending portion showed a funnel-shaped enlargement as it approached the arch. In position this vessel was shifted considerably to the left, arising from the upper third of the left ventricular border at a point considerably below the auriculoventricular sulcus. Unlike the ordinary condition, the aorta in this case followed an upward course, inclining immediately to the left so that its ascending portion was directly on the left upper ventricular wall, and only the arch came into relation with the left side of the atrium. The tip of the auricular appendix was barely touching the arch at its beginning. 
On opening the right atrium by an incision following its greatest superior curvature, it was found to consist of an apparently dilated cavity into which three openings were found, two at its posterior wall corresponding to the superior and inferior venae cavae, and one found inferiorly leading into the ventricle, the auriculoventricular orifice.

On examining the posterior wall of this atrium from the outside, four smaller vessels, presumably the four pulmonary veins, were seen, which, however, did not directly open into the large cavity described above, but into a small flattened space adjoining the posterior atrial wall, which undoubtedly represented a rudimentary left atrium. This cleft-like space was separated from the enlarged right auricle by an interatrial septum in which an oval opening guarded by a thin septum was seen. This opening which was the foramen ovale appeared normal in every respect.

No communication between the left auricle and the ventricle was found. The only communication, therefore, between the ventricle and the atrial portion of this heart was represented by the right auriculoventricular orifice, which measured approximately $42 \mathrm{~mm}$. in circumference.

Internally the ventricular portion of this heart showed only a single vertically elongated cavity, in which no recognizable division between a right and a left portion could be found. There was, however, a more or less prominent ridge situated in the middle of the posterior wall of the cavity, which by its position could be considered as representing the septum interventriculare (figs. 5 and 6). If such were the case, then this heart would have undivided right and left ventricles in their embryological condition, closely resembling in this manner the amphibian type of heart. The right portion of this ventricular cavity was in direct communication with the single enlarged atrium. The left side was continued upward and posteriorly to form the root of the aorta, while anterosuperiorly it gradually merged with a small elongated blind space found inside the peculiarly bulging portion of the anterior surface of the base of the ventricle (fig. 4).

The ventricular wall as a whole was massive, averaging about $6 \mathrm{~mm}$. in thickness. Two small papillary muscles were present, 
one situated in front and the other posteriorly, with their cordae tendinae attached to the edges of the flaps of the single auriculoventricular orifice. This opening possessed but two flaps, differing in this respect from the normal, which has three.

The aortic opening, as in normal hearts, was guarded by three semilunar cusps, two found anteriorly and one posteriorly. The three aortic sinuses (sinuses of Valsalva), were found to be dipping down into the wall of the ventricle to a much greater extent than in normal cases. The ascending aorta, as noted above, was funnel-shaped and joined the aortic arch upward posteriorly. The latter was likewise fairly dilated.

Only the right coronary artery originated from the right aortic sinus. It coursed downward in a zigzag direction for a short distance in the posterior coronary sulcus, which it soon left to run along the posterior or diaphragmatic surface of the heart, curving toward the left border considerably above the apex, and anastomosing at this point in a plexiform manner with the anterior descending branch of the left vessel. The left coronary arose directly from the anterior wall of the ascending aorta. On reaching the level of the root of this vessel in its descent, it followed forward and to the right, the anterior coronary sulcus under cover of the right auricle until it reached its extreme right end; thence the artery coursed along the right ventricular margin as far as the apex, where it resolved into plexiform anastomoses.

Another striking anomaly found in connection with the aorta was the presence of two fairly good-sized branches originating from its posterior wall about half a centimeter from its proximal end. These vessels were found to correspond with the right and left pulmonary arteries, the common pulmonary trunk being absent. This peculiar condition was not noticed until after the removal of the heart, and the identification of these two vessels was based upon a careful search and topographic comparison of their cut cardiac and pulmonary ends. The diameters of these two vessels were approximately $4 \mathrm{~mm}$. for the right and $3 \mathrm{~mm}$. for the left. 


\section{REVIEW OF LITERATURE}

In reviewing the literature at our command for cases showing similar cardiac malformations, we found the following:

1. Three-chambered hearts. Keith ('09), in his extensive review of 272 cases, established three types of three-chambered hearts, viz., a) hearts in which the interventricular septum was so little developed, or in which the interventricular foramen was so large that the two ventricles were rightly said to form one chamber; $b$ ) those cases where the right ventricle was suppressed by the septum's being applied to the right side of the heart, and, c) those in which the left ventricle was suppressed by the interventricular septum closely shifted to the left ventricle wall of the ventricle.

He found in his set nine cases belonging to the first type with associated arterial transpositions; seven cases to the second type, five of which showed complete obliteration of the right ventricle and two with the two ventricles forming a common chamber, and in every case the infundibulum was well developed. Of the third type he found five cases. In the second and third groups the absence of a ventricle was associated with a complete or almost complete obliteration of the corresponding auriculoventricular orifice.

Young ('07) and Dixon Mann ('07) reported a case of an adult man aged 35 years whose heart showed complete absence of the septum interventriculare with associated transposition of the arterial trunks. Paterson ('08-'09) reported a similar cardiac malformation in a man 22 years old. Both cases belong properly to the second type.

Gladstone ('15-'16) eited two cases of this cardiac anomaly, one from a child 48 hours old where the left ventricle was rudimentary and functionless and which therefore would fall under group 3, and the other case, a woman 50 years of age with a heart showing a patent foramen interventriculare with constriction of the ostium bulbi; which could be included under type 1 .

Dickson and Frazer ('13) had a case in a male child 3 months old. The specimen showed a hypertrophy of both ventricles 
with incomplete development of the interventricular septum. This instance could be included in the first type. It was asso ciated with an abnormal origin of the pulmonary artery.

Keith ('12) mentioned four other cases where the interventricular foramen showed varying degrees of patency found in individuals from 9 months to 16 years of age, associated with such anomalies as closure of the auriculoventricular orifice, undeveloped ventricle, and closure of the pulmonary orifice, etc. Three of these cases properly belonged to the first type, but one case, with undeveloped condition of the right ventricle, could also be considered as belonging to type 2 . He also cited a case of a child 48 hours old where the heart showed obliteration of the left ventricle and the corresponding auriculoventricular orifice. This case of course belonged to type 3 .

Black ('13-14) reported two cases: one heart, belonging to an adult male 22 years of age, showed a large interventricular foramen with associated malformations of the pulmonary cusps; the other was that of a male child 6 months old with a patent foramen interventriculare and a marked reduction of the size of the aorta with no associated anomaly of the infundibulum. These two might rightly be included under type 1 .

Our first case belongs to type 2 , as it shows a diminutive right ventricle with the interventricular septum shifted to the right side. The second case that had an incomplete septum is to be included in type 1 of Keith's classification. In case 1 there was a complete obliteration of the right auriculoventricular orifice from fusion of the flaps. Case 2 showed a complete absence of the mitral opening.

2. Arrest in the developmental expansion of the infundibulum: Keith ('09) encountered thirty-seven cases of such condition. The typical picture of such cases had the infundibulum reduced to a mere slit situated at the orifice of the pulmonary artery which was generally represented by a small cicatricial mass, or a very small lumen in which the fused semilunar valves could be distinguished. The pulmonary artery was in the majority of cases represented by a fibrous cord at its origin. 
In the case of Dickson and Fraser ('13) the right pulmonary artery originated from a point $\frac{1}{2}$ inch above the commencement of the ascending aorta and the left from the descending portion.

Keith ('12) mentioned a case in a male child 11 months old where the infundibulum was obliterated and the pulmonary artery received blood from the ductus arteriosus.

Peterson's ('08-'09) case showed besides, a marked stenosis of the pulmonary orifice with a substitution of the pulmonary valves by a thick pad of cardiac tissue.

In our cases, the first showed the pulmonary arterial trunk markedly reduced in size and the pulmonary orifice entirely closed from fusion of the semilunar flaps. In the second case the pulmonary trunk was entirely absent, and the two small arterial vessels identified as the pulmonary arteries were seen arising from the posterior side of the aorta.

3. Atrophy of the auricular portion of the heart. Keith ('09) met three cases which showed considerable diminution in the size of the left auricle associated with complete stenosis of the mitral orifice. He stated that such cases might easily have escaped detection and could have been considered as twochambered hearts - a rare condition which, even with his wide experience on the subject, he had never yet seen.

Our second case shows undeveloped left atrium together with absence of the left auriculoventricular orifice.

4. Incomplete separation of the aorta and pulmonary artery. Irregularities in the division of the truncus arteriosus, which becomes divided to form the root of the aorta and the pulmonary artery, according to Keith, are rare. He had only seen three cases in his series. Rakitansky reported a case with this condition, but with the pulmonary artery considerably larger than that found in our case.

Our second case showed incomplete separation of the pulmonary artery from the ascending aorta and two small vessels representing the pulmonary arteries arising directly from the posterior side of the beginning of the aortic root, which in turn was considerably shifted to the left side of the heart. 


\section{EMBRYOLOGICAL CONSIDERATIONS}

Owing to the various possibilities which could be considered in our cases, it would seem rather difficult to definitely offer any explanation that would adequately cover the different embryological factors which might have led to the production of the anomalies herein enumerated.

1. Monoventricular condition. In our first case we encountered a suppression of the right ventricle by the septum's being applied to the right side of the heart. In the second case the two ventricles were imperfectly separated by defects in the interventricular septum:

We have failed to find in our search of the literature any author who endeavored to explain the first condition.

It is a well-known fact that at some stage of the normal development of the heart there is a time when the so-called ventricular limb starts its division into a greater left and a smaller right half, to be later known as the left and right ventricles, respectively, by the production on its external convex surface of a groove and within its cavity of an interventricular septum.

If at this period of development by some unknown reason the normal proportionate development of parts were arrested or at least changed to an unequal growth, similar anomalies would probably result. Thus if we were to suppose at this stage a delayed or even an arrested growth of the right side of the heart, with consequent continued and relatively increased development of the left, a condition would result where the left cardiac cavity would appear greatly enlarged, with the septum apparently reduced to a mere parietal thickening shifted well to the right, and the right ventricular cavity represented by mere crevices or by a diminutive cavity hardly large enough to permit the unfolding of the tricuspid valves. This condition is exactly similar to that encountered in our first specimen.

Our second case of monoventricular heart with imperfect separation of the two ventricles by defect in the interventricular septum has been encountered and explained by several writers on this subject. Gladstone explains the persistence of the inter- 
ventricular foramen as an apparently secondary condition to the failure in the expansion of the bulbar portion of the right ventricle, and says that its presence and size depend largely upon the extent of the defect. Hunter and Keith hold the same view, i.e., that the interventricular foramen is produced by the obstruction or stenosis of the pulmonary artery and that the closure of the interventricular foramen depends on the complete development of the infundibulum. Keith further states that from $\mathbf{8 5}$ to 90 per cent of the cases with pulmonary stenosis showed an interventricular foramen.

Meckel, as cited by Keith ('09), claimed, on the other hand, that the interventricular foramen is a primary condition and the pulmonary stenosis its sequence.

Young asserts that the course of the main blood-stream inside of the heart could interfere with the complete development of the interventricular septum.

The monoventricular condition in our second case may be explained perhaps by an arrest of growth of the interventricular septum, which in this case is represented by a mere ridge in the ventricular floor. This septal condition is similar to its early stage of development in the division of the embryonic ventricle into two halves. This arrest is undoubtedly due to the mechanical pressure and friction exerted upon it by the flow of blood coming through the right auriculoventricular orifice and which not finding any exit at the right ventricular side because of the total absence of a pulmonary artery is forced toward the left side of the ventricle to find there its only orifice of escape represented by the aorta (fig. 8).

The abnormal and excessive upward prominence of the ventricular wall in its anterosuperior base must also be looked upon as a necessary result of the same continued increased pressure exerted upon that part of the ventricle by the blood-stream passing through the aortic orifice. This influence is certainly conceivable, if we remember that the arterial pulmonary trunk should have taken origin from this region, and that the tender embryonic cardiac musculature is very apt to give way to such a persistent and continued mechanical factor. 
2. Congenital stenosis of the pulmonary orifice with or without arrest of the developmental expansion of the infundibulum. Keith explains the majority of those cases of congenital pulmonary stenosis associated with arrested development of the infundibulum as due to a failure of the bulbus cordis to incorporate with the right ventricle. In those cases where the stenosis is not, however, associated with an arrested infundibulum, he believes foetal endocarditis to be responsible for the defect.

In this connection we quote from Gladstone the following:

According to Schipman, the most common and important effect of intra-uterine endocarditis is stenosis of the pulmonary orifice, and he also states that the limitation of the endocarditis to the right side of the organ during intra-uterine life comes under the same law as its limitation to the left side in extra-uterine life. In both cases it is the cavity which has most work to perform that is affected. According to this view, cases in which the interventricular foramen has not persisted are produced by endocarditis occurring after the period when this foramen is normally closed. The closure is effected by the fusion of the interventricular septum with the bulbar septum, and this takes place in embryos between $12 \mathrm{~mm}$. and $18 \mathrm{~mm}$. in length, and at the age of six or seven weeks. It is possible, however, that the endocarditis is a secondary incident which has occurred after birth, and that the primary condition is constriction. It is probable also that the constriction is attributable to a primary defect in development rather than to a foetal endocarditis; for if foetal endocarditis were the cause, we should expect also to find stenosis of the right auriculo-ventricular orifice with endocarditis of the tricuspid valve, but this is not found, on the contrary congenital stenosis of the right auriculo-ventricular orifice is extremely rare.

In our two cases we found a complete absence of the infundibulum, associated in the first case with a diminutive pulmonary artery and stenosis of the pulmonary orifice by fusion of its similunar valves and with complete absence of the pulmonary artery and pulmonary orifice in the second.

These defects plus the absence of any inflammatory signs in the perfectly smooth and shiny fused pulmonary flaps incline us to believe that neither foetal endocarditis nor the failure of incorporation of the bulb into the right ventricle would furnish satisfactory explanations. 
In normal cases we know that the separation of the bulb into the aortic and pulmonary trunks is the result of the fusion of the right and left distal bulbar swellings and the septum aortopulmonale. These swellings are linear thickenings of the endocardial surface of the bulb, two at its proximal and four at the distal portion. The union of the right and left distal bulbar swellings is generally produced by the ingrowth of the connective tissue of the bulbar wall. This fusion together with the approaching septum aortopulmonale brings about the complete division of the bulbar trunk into a ventral vessel, the aorta and a dorsal pulmonary artery. The two proximal swellings by their spiral direction complete further this division by bringing each vessel into a more direct relation with its corresponding ventricle. The semilunar valves of the aortic trunk are formed by the anterior distal bulbar swelling and the two anterior halves of the right and left laterally. Those of the pulmonary artery by the posterior and the posterior halves of the right and left distal lateral swellings.

Now it is possible that in the first case, owing to inequality in growth of the ventricle, the union of the right and left bulbar swellings with the septum aortopulmonale has taken place, but considerably shifted to the anterior side of the bulb. This shifting has necessarily reduced the pulmonary artery to a diminutive trunk, and its semilunar valves, remaining diminutive and crowded together, have become completely fused.

In the second case the septum aortopulmonale has probably failed to descend and meet the bulbar swellings, leaving in this manner the truncus arteriosus undivided, and the pulmonary arteries arising directly from the ascending aorta. Such condition would also account for the absence of the pulmonary orifice.

3. Rudimentary and collapsed condition of the left auricle. As regards the rudimentary and collapsed state of the left atrium and the absence of its atrioventricular orifice, it does not seem possible to offer as reasonable explanations as in the anomalies already considered above, we might, however, conceive such abnormality as due to a probable combination of such two factors as: 
a. A possible arrest or entire failure of development of the two endocardial cushions which should normally appear in the ventral and dorsal walls of the heart in the region of the atrioventricular sulcus, together with fusion of this sulcus with the interatrial septum in the side of the left atrium.

b. Normally developed cushions which after their union were shifted to the left to meet and fuse with the atrioventricular sulcus in this side. This condition, if combined with an arrest of further development of the left atrium with a compensatory enlargement of the right side, would give rise to a condition similar to that found in our specimen.

Such a combination of factors influencing the production of the above abnormalities could only be made possible by the total absence or diminished amount of blood flowing into the left atrium as a result of the absence of the arterial pulmonary trunk.

The four pulmonary veins probably transmitted little blood if any at all into the left atrium, two vessels which were taken as representing the pulmonary arteries being altogether too small to carry on any appreciable pulmonary circulation.

\section{PHYSIOLOGICAL CONSIDERATIONS}

Probable cardiac circulation in the two cases. A morphological study of the circulation, both during the intra-uterine and postpartum lives, in both cases would indeed be of some interest.

Case 1. Prenatal circulation in this case is obviously possible and could normally be carried on to full term without greatly impairing the normal general development of the foetus.

The arterialized blood from the placenta undoubtedly followed a normal circuit by passing successively through the right and left atria (freely communicating with each other by a patent and relaxed foramen ovale), to the single ventricle through the widely open mitral orifice, and thence to the general circulation, passing out of the aortic root.

A satisfactory explanation of the postpartum circulation in this case would offer several difficulties. Literatures on cardiac malformations mention only a few instances where three-cham- 
bered hearts were found in adult individuals. Cases with complete atresia of the pulmonary orifice, as in the case under consideration, have never been known to live for more than twenty-four hours. In such instances where a complete arrest of the infundibulum was present, the lungs, according to Professor Keith, were supplied with blood from the systemic circulation through the bronchial arteries and other accessory branches of the intercostals. It is unfortunate that we were unable to obtain a complete clinical history of our case; this would probably have helped us in our explanation by knowing the behavior of the child after delivery.

It is of course possible to conceive that the pulmonary circulation could be carried in one of the two following ways:

$a$. The lungs may receive some blood via the bronchial arteries and intercostal branches, as explained by Professor Keith. We regret that we were unable to study the bronchial arteries of this specimen. We question, however, the ability of such circulation to sustain life for any length of time in our case because of the almost complete absence of any expanded lung tissue in either side. The child lived only two hours.

$b$. Pulmonary circulation might be possible also by the blood passing successively from the right auricle to the left atrium through the foramen ovale, thence to the left ventricle through the mitral orifice, therefrom into the aorta from which a small amount of blood could enter the ductus arteriosus in the reverse direction and eventually reach the lungs via the pulmonary artery (figs. A and B).

The great downward obliquity of the ductus arteriosus in its union with the aorta, its relatively small size, and the reverse direction of the collateral stream incline us to believe that only a small amount of blood, if any at all, could possibly reach the lungs by this route. If we add further to the above facts, the venous condition of the blood thus circulating, we almost wonder lhow the child could have lived even for two hours as it did, unless the oxygenation of its blood from the placenta could have rearried him through that length of time.

Case 2. The foetal circulation in utero in this case undoubtedly followed a similar route as in case 1. 
The postpartum circulation offers to a certain extent similar difficulties as those encountered in case 1 .

The pulmonary circulation was carried on again either by the collateral bronchopulmonary circuit of Professor Keith or through the two diminutive pulmonary arteries branching off from the aorta. In either case, however, the return circulation took place through the four diminutive pulmonary veins into the collapsed left atrium and thence through the foramen ovale into the right auricle, completing in this manner the pulmonary circuit.

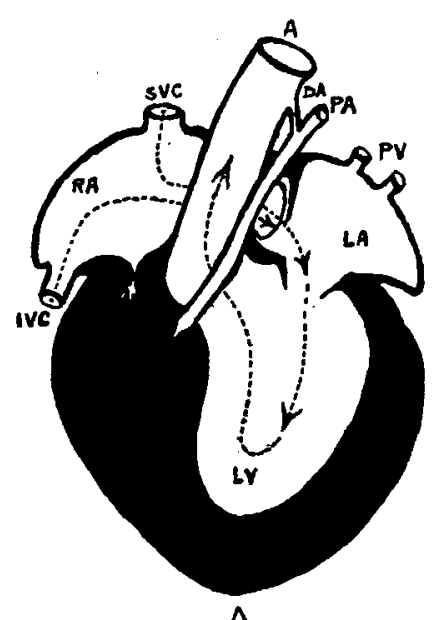

A

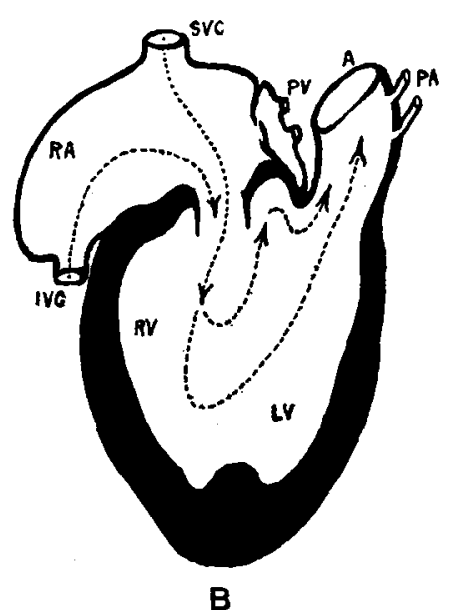

B

Fig. A Diagrammatic sketch showing probable circulation in case 1 .

Fig. B Diagrammatic sketch showing probable circulation in case 2.

$I V C$, inferior vena cava; $R A$, right atrium; $L A$, left atrium, $S V C$, superior vena cava; $A$, aorta; $D A$, ductus arteriosus; $P A$, pulmonary arteries; $P V$, pulmonary veins; $L V$, left ventricle; $R V$, right ventricle.

We believe, however, that the amount of blood reaching the lungs by any one of the above two routes, though probably was greativ in amount than in the first case, yet it was without doubt insufficient to support life for any long period. We base this opinion on the great reduction of size of the pulmonary arteries and veins (less than one-third the normal dimensions) and the diminutive collapsed condition of the left atrium, both 
of which spell a proportionately reduced blood stream in the entire circuit, which though sufficient to enable the foetus to live for a few days, is nevertheless undoubtedly incompatible with prolonged life. This case lived about four days.

\section{CONCLUSIONS}

In closing, we would like to draw attention to the following points of interest:

1. The incidence of monoventricular hearts among the Filipino babies is apparently not a very rare condition. In our series we encountered them in the proportion of 1.6 per cent. This fact would seem to call for a more careful clinical study of newly born babies showing obscure cardiac symptoms with fatal results.

2. That the ratio of the weight of the heart to the body weight in our cases was considerably greater than the normal ratio as given by Jackson and Vierordt, denoting undoubtedly a compensatory effort on the part of the heart to carry on circulation under abnormal conditions.

3 . That not all cases of persistent interventricular foramen can be explained by the failure of expansion of the bulbar portion of the right ventricle or by pulmonary stenosis produced by foetal endocarditis. In many instances it is necessary to invoke also defects of growth, mechanical effect of abnormal blood stream, etc.

4. That the congenital atresia and stenosis of the pulmonary orifice in our cases was probably due to either irregularity of growth of the ventricle and shifting to one side of the union of the right and left bulbar swellings and the septum aortopulmonale or to the entire failure of the septum aortopulmonale to unite with the distal lateral bulbar swellings.

5. That monoventricular hearts are perfectly compatible with normal development in intra-uterine life, but when associated with pulmonary stenosis, even with patency of the ductus arteriosus, it is probable that life cannot continue for more than a few days, although the collateral pulmonary circulation might be taken up by branches of the bronchial and intercostal arteries. 
I wish to acknowledge my indebtedness to Dr. H. W. Wade, of the Department of Pathology, for allowing me to report case 2, which came' to them at the autopsy table, and to Dr. Arturo Garcia for some helpful suggestions in the preparation of this paper.

\section{LITERATURE CITED}

BLACK, DAVIDSon 1913-14 Two cases of cardiac malformation-more especially of the infundibular region. Journal of Anatomy and Physiology, vol. 48 , p. 274.

Dickson AND Fraser 1913 A congenital abnormality of the heart and bloodvessels. Journal of Anatomy and Physiology, vol. 48, p. 210.

Gladstone, R. J. 1915-16 Two examples of cardiac malformation. Journal of Anatomy and Physiology, vol. 50, p. 228.

Keith, Arthur 1909 Malformations of the heart. Lancet, vol.'2, pp. 359, 433 , and 519 .

1912 Six specimens of abnormal heart. Journal of Anatomy and Physiology, vol. 41, p. 190.

Mann, J. Dixon 1907 Cor Triloculare Biatriatum. Brit. Medical Journal, vol. 1, March 16.

Paterson 1908-9 Congenital malformed heart. Jour. of Anatomy and Physiology, vol. 43 , p. lv.

Young, A. H. 1907 Rare anomaly of the human heart-A three-chambered heart in an adult aged thirty-five years. Journal of Anatomy and Physiology, vol. 41, p. 190. 


\section{PLATES}


PLATE 1

EXPLANATION OF FIGURES

1 Anterior view of heart of Case 1. A. Anterior coronary artery and great cardiac vein. B. Aorta. C. Pulmonary artery.

2 Anterior half of coronal section of above heart (case 1). A. Aortic orifice. B. Right auricle. C. Crevices representing remains of right ventricle. V. Ventricle (single).

3 Posterior half of coronal section of above heart (case 1). B. Right auricle. C. Crevices representing remains of right ventricle. D. Ventricle (single). E. Left auricle. 

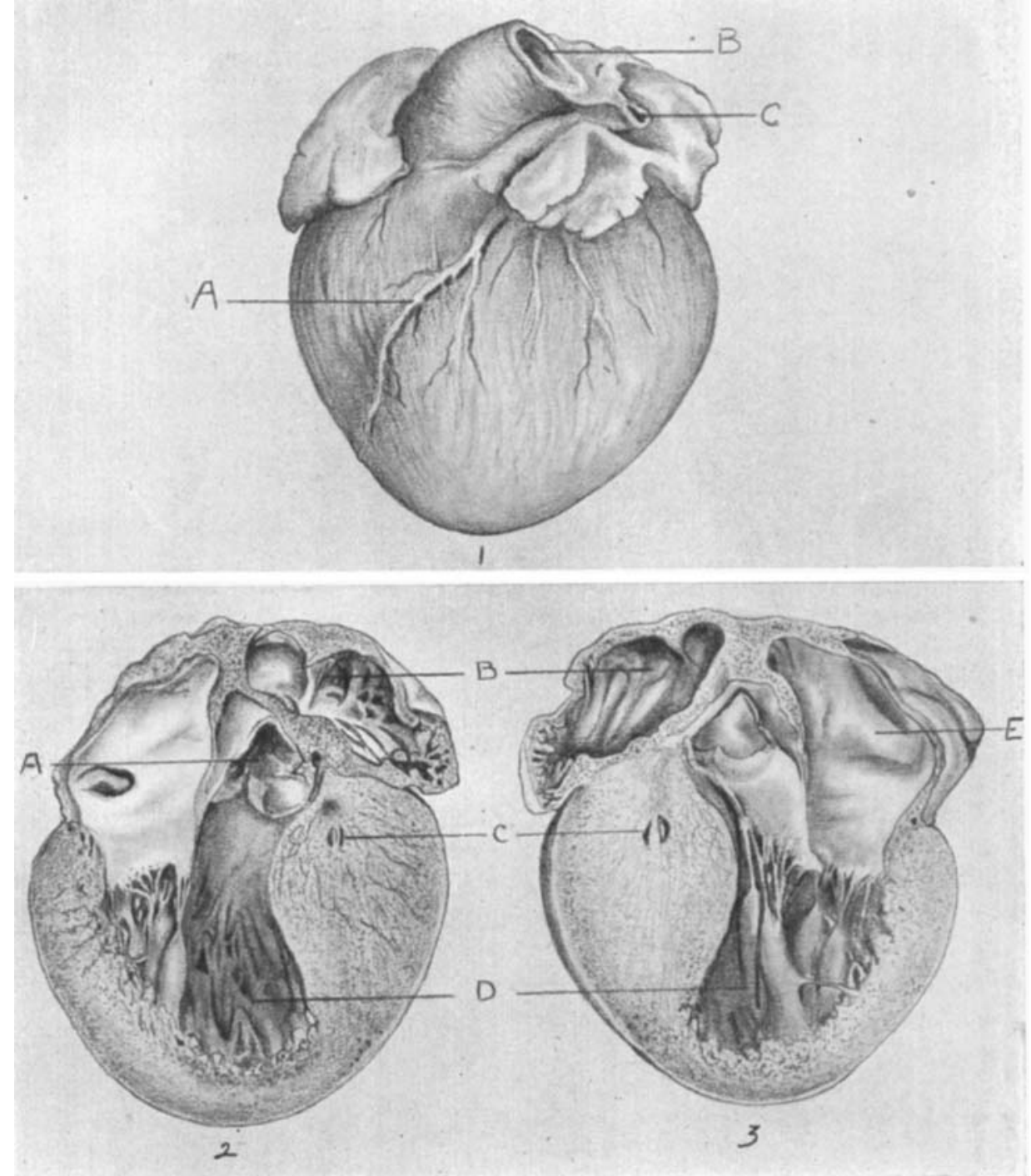

TEE ANATOMICAL RECORD, VOL. 20, NO. 3 


\section{PLATE 2}

\section{EXPLANATION OF FIGURES}

4 Anterior view of heart of case 2. A. Right auricle. B. Aorta. C. Ventricle.

5 Anterior half of coronal section of above heart (case 2). A. Thickened upper part of left wall of single ventricle. B. Right atrium. C. Single ventricle.

6 Posterior half of coronal section of above heart (case 2). B. Thickened upper part of left wall of single ventricle. C. Single ventricle. D. Descending aorta. F. Foramen ovale. 

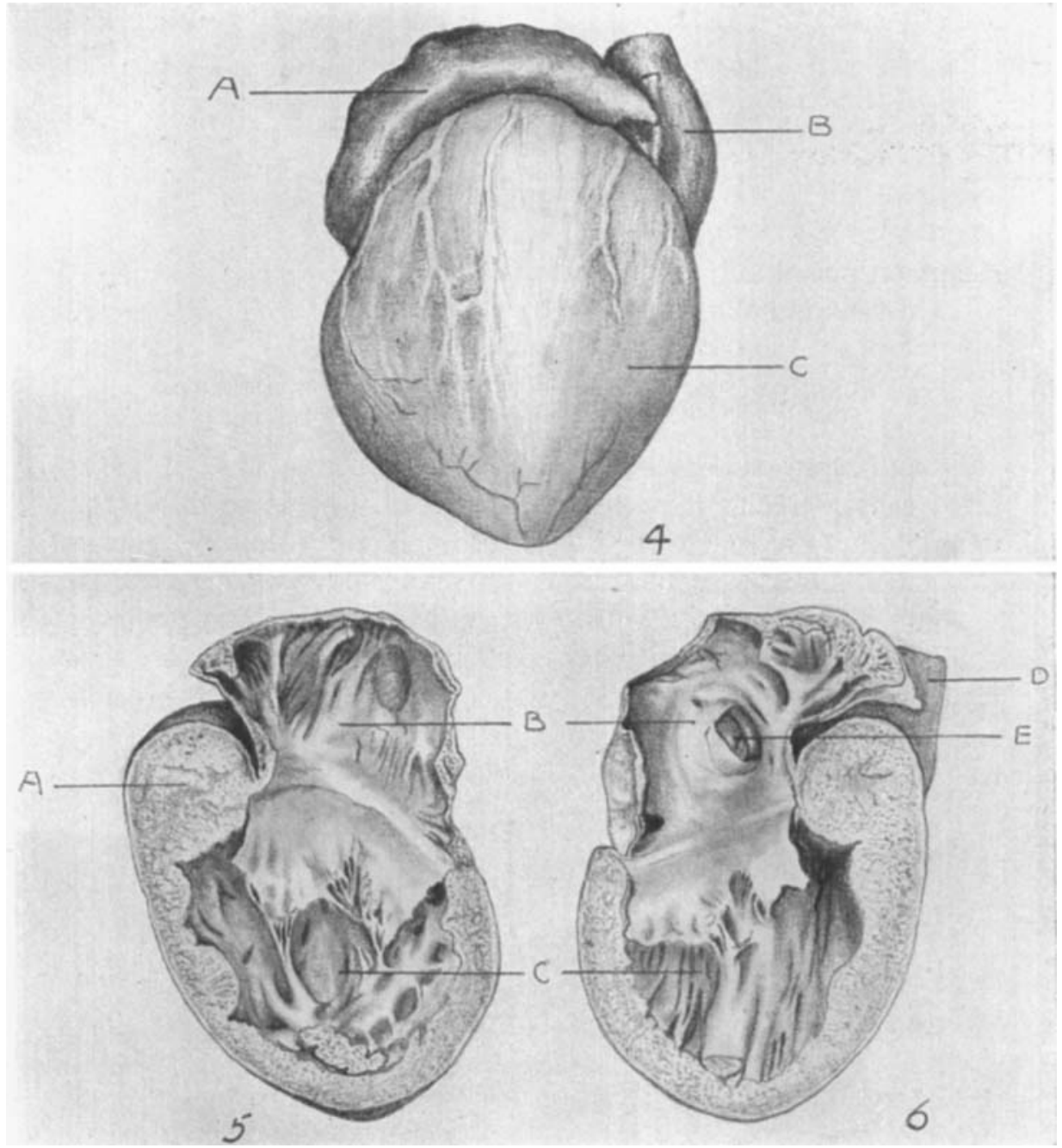